\title{
'I am just so delighted - now I know I can do it!' - How collaboration between Nurse Lecturers and Academic Skills Tutors promotes students' confidence
}

\author{
Celia Butters \\ Glyndŵr University, UK
}

\section{Sheila Kerfoot}

Glyndŵr University, UK

\section{Peggy Murphy}

Bangor University, UK

\author{
Alison Williams \\ Glyndŵr University, UK
}

\section{Abstract}

This paper showcases two collaborative projects between Academic Skills Tutors and Nurse Lecturers aimed at increasing students' writing and numerical skills. Both projects work proactively with students to increase their potential to succeed. Feedforward works on developing students' academic writing skills and the Numerate project develops their confidence with numbers. The collaboration has had a positive effect on student retention within the university's pre-registration nursing course. The feedback from students suggests that these interventions have helped to increase their confidence in their ability to learn.

Keywords: proactive; collaboration; development; confidence; Feedforward; feedback; retention; assessment; numeracy; Numerate; drug calculations; student engagement and student success. 


\section{Introduction}

Any projects that are directed towards promoting student success need to be inclusive of the entire student population. Glyndŵr University $(2011 / 12$ - 2013/14) has a high proportion of students with a disclosed disability, $19.8 \%$ of the entire student body. In nursing, however, this figure is much higher. The pre-registration nursing periodic review (Glyndwr, 2011) records that $35 \%$ of pre-registration nursing students receive Disabled Student Allowance (DSA) with most of them reporting dyslexia. These two projects were designed not only to identify learning needs early on, in the case of Feedforward, but each project also acknowledged diversity within the student population. Any teaching and learning strategy aiming to address the needs of student diversity helps to enhance the learning of all students. Both Feedforward and Numerate were designed to help all students to feel more confident about the transition from one level of study to another. In the case of Feedforward it was from level 3 to level 4.

Academic skills and numeracy support is also available for all students via the Academic Skills Centre which is based in the university library in an area which is highly visible. The Academic Skills Tutors (ASTs) hope that visiting the centre will be seen by students as normal behaviour when visiting the library. Staff work with students in full view, thereby seeking to normalise the process and to dispel any idea of its activities having a remedial focus (although semi-private screened areas are available if students prefer this or are distressed).

The main reasons cited by students for their attendance at the Academic Skills Centre are for support in the structure of work, help with the referencing of sources and for reassurance. Confidence-building is often a large part of any interaction with students who attend the university's Academic Skills Centre. Students often seek reassurance that they 'are on the right lines' or have 'got the right idea'. ASTs introduce an element of mentoring or coaching to many students who seem to lack confidence in their abilities. They are well placed to offer this since they stand outside the subject area and can be seen by students as a 'safe' person to whom they can express their worries. As an illustration of the Academic Skills team's work, we offer the following vignette: A despairing student was considering giving up her studies. She had not achieved a mark higher than $42 \%$ in semester 1 due to her inability to express herself clearly and to organise the structure of her work. After fortnightly meetings with an AST over semester 2 , she telephoned to inform 
us she had received marks for her three assignments: $63 \%, 65 \%$ and $66 \%$. She said 'I am just so delighted - now I know I can do it!'.

\section{Literature review}

Being under-prepared for tertiary level study is nothing new. Tinto (1975) identified it as a reason for students dropping out of their studies more than 35 years ago. More recently, lack of preparedness for study was still one of several reasons given by students for noncompletion of their programmes (National Audit Office, 2007). One of the factors cited by students was not having the study skills in place for success (National Audit Office, 2007).

Some recent studies have concluded that while the ability to write well at university may be assumed by lecturers, the reality can be somewhat different (inter alia Coffin et al., 2003; Moon, 2005; Ganobcsik-Williams, 2006; Crabtree et al., 2007; Groves et al., 2010; Johnston, 2010; Wingate and Andon, 2011). Some studies acknowledge that, while an assumption of competent written ability may have been understandable at one time, the changing nature of the student body (increased numbers, increasing diversity, widening participation) has led to its no longer being justified.

The National Union of Students (NUS) has recognised the need for its members to develop effective study skills and has launched a charter with recommendations for the provision of study skills support (NUS, 2012). It states that academic support is vital to give students confidence to continue their studies. The charter incorporates recommendations for students to be given information about the academic support provision available so that key messages about study skills are received at various points throughout a student's programme of study.

It is recognised that student success is dependent upon early engagement with higher education (HE) (Thomas, 2012). Working with the students early on is essential but it is also crucial that students who require support establish early engagement with all of the services that the university offers. Inherent within this though, is students' perception of their need for study skills support. Some may consider that their academic writing is perfectly adequate and may consider the lecturer who gives them a low mark to be a "hard marker' (it is perceived that the low mark is the fault of the lecturer, not the student). 
Others may be crushed by the low mark and feel too embarrassed or ashamed to seek help. As Knowles et al. (1998) assert, where adults feel that their experiences are devalued, for example, in the low mark for what a student may consider to be a wellwritten essay, then adults will perceive this as a rejection of themselves as persons. This may account (at least in part) for the student who decides that university is not for them and drops out of their course. It is an important point; Yorke (2003) found that students may lose confidence if the distinction between product and person is not made. Therefore, it is good practice to ensure that the language used in feedback makes it clear that the comments refer to the work and not to the student.

Boone (2010) identifies the student 'wounded writer' who has not experienced adequacy in writing and argues that outcomes for basic writers are powerfully contingent on how they are introduced to academic writing. The authors agree, and would add that if the basics of academic writing are not introduced at an early stage then it would not be surprising if students flounder when they write their first assignments.

What is being asked of students is quite complex. They are required to plan their assignments, read effectively, analyse evidence, write well, use appropriate citation and referencing, structure their work and demonstrate their content knowledge. Perhaps in recognition of this, Moon (2005) declares that an input at the beginning of a programme alone is hardly likely to be adequate. While expounding the view that the teaching of writing should be seen principally as a developmental and not a remedial process, she cites the need for multiple inputs, including some for postgraduate students who may need support with writing theses.

Cottrell (2001, p.9), makes the distinction between subject knowledge and study skills thus: 'Study skills development is not an alternative to the knowledge base but a way of enhancing learning potential so that the knowledge is more accessible and better understood'. This elegant explanation of the role of study skills could help students to realise the importance of developing their skills and to appreciate the link between the acquisition of study skills and the successful completion of a programme of study.

Students are increasingly anxious about maths testing within nurse education and this anxiety has been further compounded by the need to achieve a $100 \%$ pass rate in drug calculations prior to registration (Nursing and Midwifery Council (NMC), 2010). Anxiety 
surrounding maths can begin early in school life (Roykenes and Larson, 2010). Studies by Walsh (2008) acknowledge the link between nursing students and maths anxiety, and Glaister (2007) contends that the fear of maths can often have a negative impact on the students' ability to learn. By working collaboratively, ASTs and lecturers can help to allay some of the fears surrounding maths by way of building the students' confidence on commencement of the nursing programme.

The students' anxiety about mathematical ability is shared by the regulatory body for nursing, the Nursing and Midwifery Council (NMC). The NMC have responded to concerns about the numerical impact surrounding safe administration of medications by introducing gateways that must be achieved at certain points within the nurse education three year programme (NMC, 2010). Accordingly, the NMC (2010) recommend that Higher Educational Institutions (HEls) incorporate numeracy testing within the pre-registration nursing programme. Furthermore, at the point of entry onto the professional register, a $100 \%$ pass mark must be achieved in medication related calculations. In response to these requirements the newly validated BSc Nursing programme, which commenced September 2012, incorporates summative numeracy assessment at the end of all three years. At the end of year one the mark required is $80 \%$, rising to $90 \%$ at the end of year two with $100 \%$ required at the end of year three. Moreover, once they have been admitted to the professional nursing register students now have to undertake a numeracy assessment prior to interview for nursing posts within the Local Health Board.

It was as a result of student anxiety surrounding mathematics that the authors decided to introduce additional sessions, known as Numerate, which were jointly facilitated by the Academic Lecturer and the AST. Team teaching these sessions proved particularly effective, providing the students with the underpinning mathematical knowledge whilst linking the theory behind the mathematical formula to a 'real' nursing scenario.

\section{Focus of collaboration}

In the university's nursing department we understand that ASTs as well as academic staff are essential in helping students to develop essay writing and numeracy skills, and we work in partnership to support students. The ASTs are invited to address the new cohorts of students during their first week in university to inform them of the support available to all 
students with both numeracy for drug calculations and academic writing. During this first week, students are also provided with a tour of the library facilities and are shown the resources (such as study skills books and study skills resources on the virtual learning environment (Moodle) provided at the Academic Skills Centre. Facilitating the students to work with ASTs in the first module is a way to proactively manage student transition from Further Education (FE) to HE. First year students are in an unfamiliar environment, working with difficult new material and surrounded by strangers. Falling into familiar study habits may provide some comforting semblance of a known routine. However, if those study habits are ineffective or counter-productive, a discussion with a lecturer or AST may help the under-confident student to achieve more by working differently. Of course, this presupposes that a student will have the confidence and motivation to seek out someone with whom to discuss their study methods. Where students choose not to take this route, they may continue with ineffective study methods which could impact upon their academic achievement and their levels of confidence in their academic ability. This is where lecturers in specific subject areas can help by signposting their students to the support available from ASTs.

The Feedforward project encourages students to make the connection between assessment, feedback and learning. It also gives students the opportunity to reflect upon early formative feedback and think about designing their own strategy for succeeding. The project was initially offered to new students on the university pre-registration nursing programme but Feedforward is now also offered at levels five, six and seven. Support is therefore available to students for both subject knowledge and study skills development.

With regard to numeracy support, ASTs and nursing lecturers work closely together during the first year of the pre-registration nursing programme to provide the underpinning numerical knowledge required to calculate drug dosages safely, whilst second year nursing students were alerted to the opportunity to update their numerical skills via the Numerate project. This project aimed to improve student numerical confidence and skills in line with the new NMC (2010) requirements of $100 \%$ competency in dosage calculations at the point of registration. It also encouraged independent learning whilst developing a deeper understanding and appreciation of the skills required for accurate drug calculation. Moreover it addressed potential issues of retention in light of the new NMC (2010) requirements which required $100 \%$ pass in medication related calculations at the point of point of entry to the register. 


\section{Description of Feedforward intervention}

Pre-registration nursing students are required to start writing their first assignment in the first couple of weeks of commencing their university course. This can be a critical time for students and some struggle to cope with the transition from FE to HE. If we can help students to produce at least a reasonable first assignment they can use this as a platform to build their confidence. The feedback offered (as Feedforward) not only helps develop subject knowledge, but also their writing ability. If the first assignment contains too much critical feedback and a low mark without advising the student how to put things right, new students can become discouraged and may start to think about withdrawing from their studies.

\section{Figure 1. Timetable of Feedforward.}

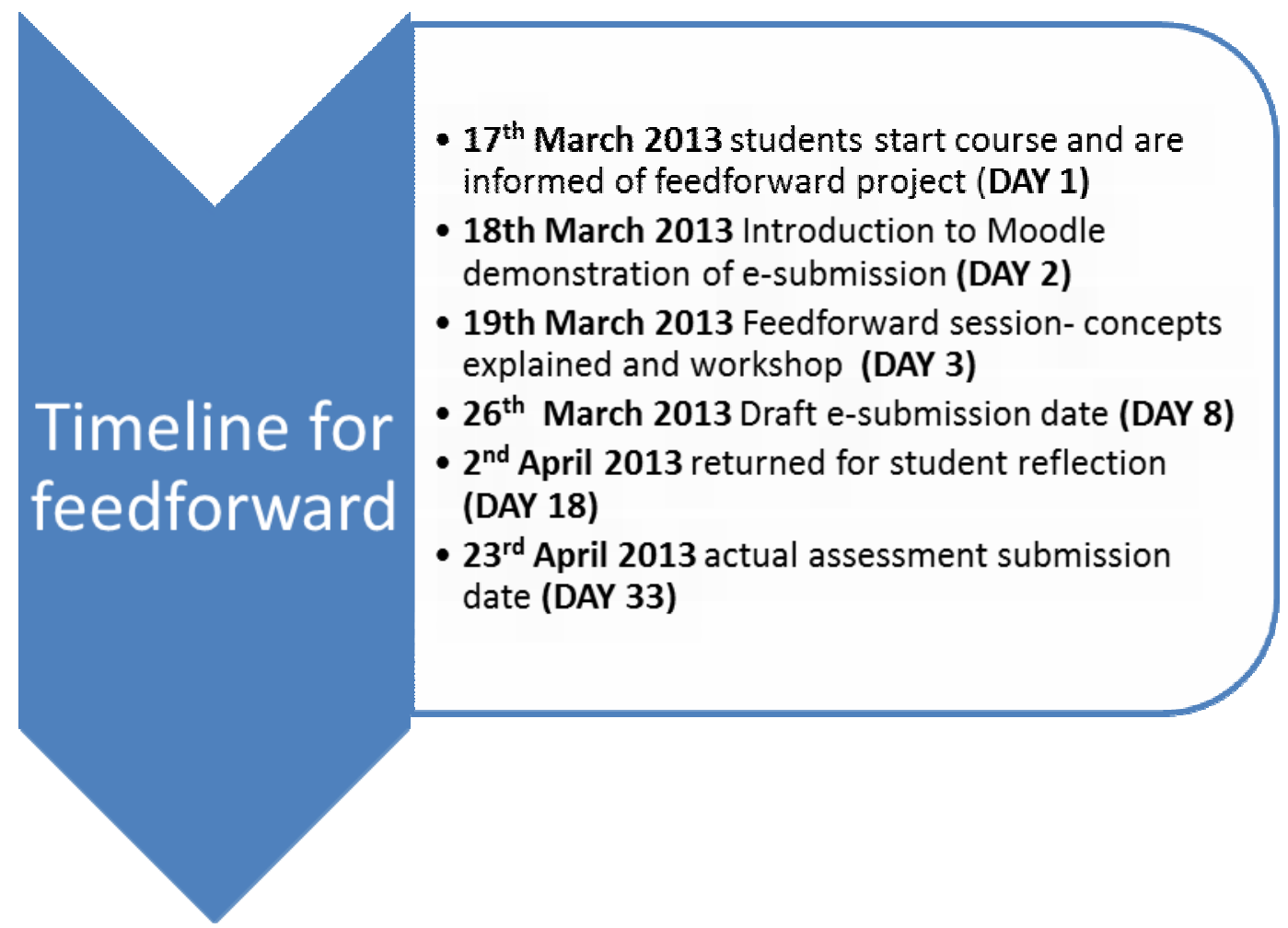

The Feedforward project keeps to a tight time frame to ensure that the students engage from the first week of the programme (see Figure 1). Students are informed about the project on their first day and the assignment brief is launched later that week. Feedforward promotes learning through a collaborative process involving the student, the academic tutor and, for a number of students, the ASTs (see Figure 2. Cycle of Feedforward to promote student engagement and learning). The time frame is structured to allow the 
students time to reflect on their own and the tutor's comments and act upon suggestions prior to their submission date.

Figure 2. Cycle of Feedforward to promote student engagement and learning.

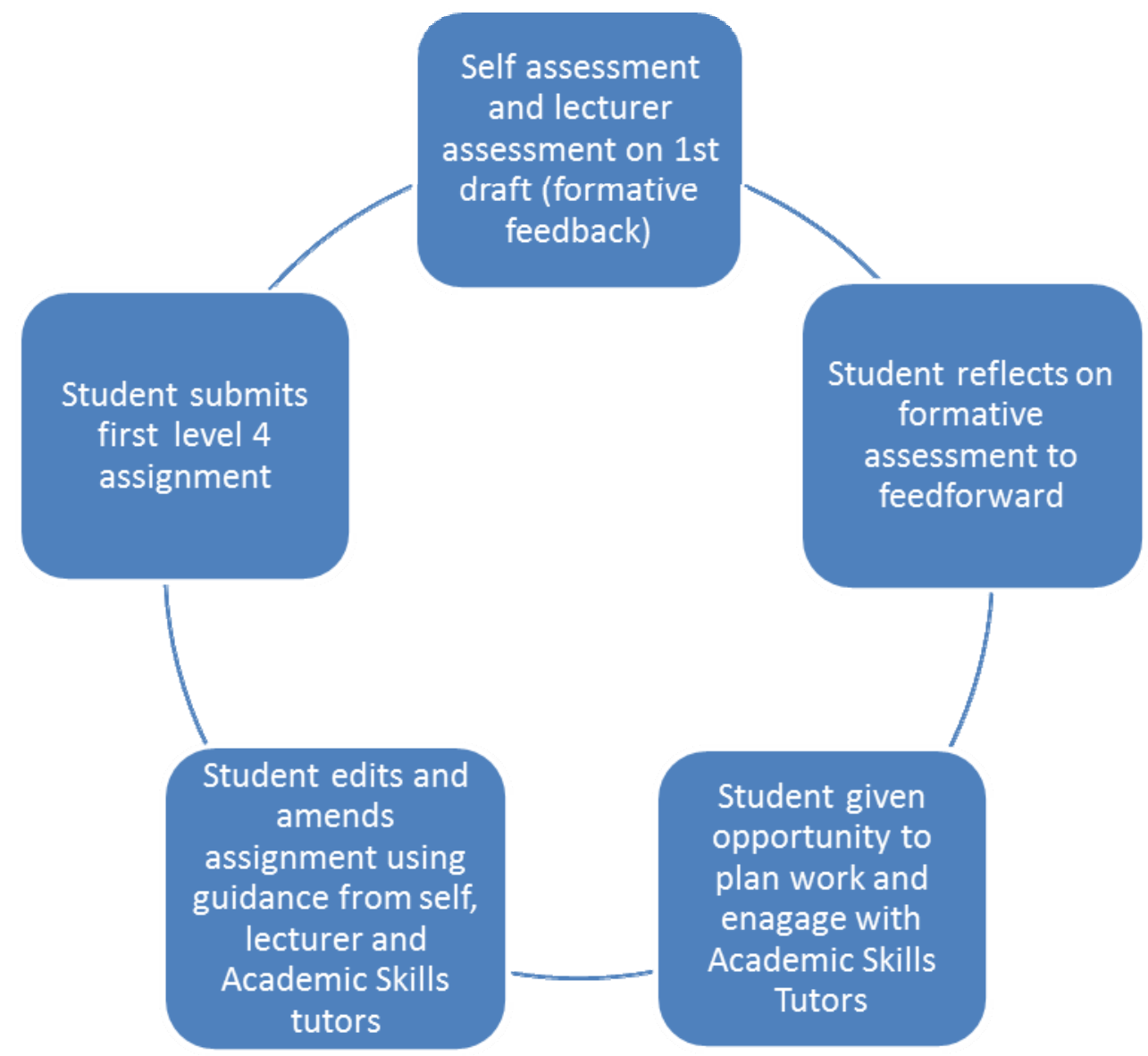

Students are given a structured timeline of when to submit their draft so they can receive practical written feedback on how to improve their work. They are given an 'edit your own draft' checklist (see Figure 3) to encourage them into the habit of assessing their own work. They also receive a projected mark, together with detailed written feedback, to give them information on how to close the gap between their actual and their required (or desired) performance. Another important proactive element of this work is that it gives the academic tutor the opportunity to assess whether students need signposting to any of the support services. 
Figure 3. Edit your own draft.

\begin{tabular}{|l|l|l|}
\hline Question & Yes/No & Comments \\
\hline Have I interpreted the assignment brief? & & \\
\hline $\begin{array}{l}\text { Does the introduction clearly state the } \\
\text { intention and structure of my essay? }\end{array}$ & & \\
\hline $\begin{array}{l}\text { Is the answer well-structured and written } \\
\text { in a logical sequence? }\end{array}$ & \\
\hline $\begin{array}{l}\text { Does the essay move fluidly from one } \\
\text { paragraph to the next? }\end{array}$ & \\
\hline $\begin{array}{l}\text { Are the arguments clear and based upon } \\
\text { evidence from the literature? }\end{array}$ & \\
\hline $\begin{array}{l}\text { Have I supported each argument with } \\
\text { references and examples from the } \\
\text { literature? }\end{array}$ & \\
\hline $\begin{array}{l}\text { Have I answered all of the main points? } \\
\text { descriptive writing that was not essential? }\end{array}$ & \\
\hline $\begin{array}{l}\text { Have I avoided including any new } \\
\text { information in my conclusion? }\end{array}$ & \\
\hline $\begin{array}{l}\text { Does the conclusion tie in with my } \\
\text { introduction and main body? } \\
\text { depth to demonstrate learning? }\end{array}$ & \\
\hline $\begin{array}{l}\text { Have I provided references throughout } \\
\text { the essay and a list at the end? }\end{array}$ & \\
\hline $\begin{array}{l}\text { Have I removed any less significant } \\
\text { aved each point in suffient }\end{array}$ & \\
\hline
\end{tabular}


If any student receives a projected score of $45 \%$ or below they are advised to book a tutorial with one of the ASTs who can tailor academic skills support specifically for individual learning needs.

Burke (2011) noted that it was the more academic students who would collect their annotated assessments. She established that out of the pile of assessments that were not collected by her students most were failed assignments. This suggests that students who need feedback most are the least likely to access it. Feedforward aims to proactively engage all students, regardless of ability, to see that they can affect their own marks. It enables students to plot their own learning trajectory by collaborating with academic and ASTs and using feedback constructively.

\section{How Feedforward engages students}

The project aims to help students make sense of their feedback. Every draft was annotated by the tutor with practical advice on how to improve their assignment before submission. Weaver (2006) found that despite knowing how crucial feedback is to learning, educationalists spend little time explaining what the feedback means to students. She found that $75 \%$ of students receive no guidance on how to apply feedback before entering HE, and Hattie and Timperley (2007) found that $50 \%$ of students in HE receive no guidance about what to do with their feedback. This is where working with ASTs can help students make sense of what is required of them. ASTs can help to unpack the 'educational speak' and develop students' understanding of feedback by explaining how they can improve their work.

Feedforward gives students an opportunity to reflect on written feedback to improve their work prior to the final submission. Students also receive a projected mark so that they can measure their progress from draft to actual submission. Students learn that working with ASTs can improve their projected mark. They also begin to understand the importance of engaging with feedback for learning. When feedback is only offered summatively students can feel passive as it highlights mistakes at a time when they cannot rectify them. This project offers sound advice on what parts they did well, as well as how to address the weaker elements prior to final submission. Feedforward is provided in sufficient time for 
the student to reflect upon advice and increase their chance of success. Students can therefore move from being passive to active participants in the feedback cycle.

\section{Evidence of impact}

Most students who engaged with Feedfoward improved their work. This was measured by plotting their projected mark and comparing it to the actual mark (see Figure 4). This graph below shows that out of one cohort of nursing students, 15 of the 21 participants improved their marks between 5-10 per cent. From the other 6 participants, 4 students' marks did not alter throughout the project and 2 scored less in their actual mark than the projected Feedforward mark.

Figure 4. Projected Feedforward mark and actual mark achieved.

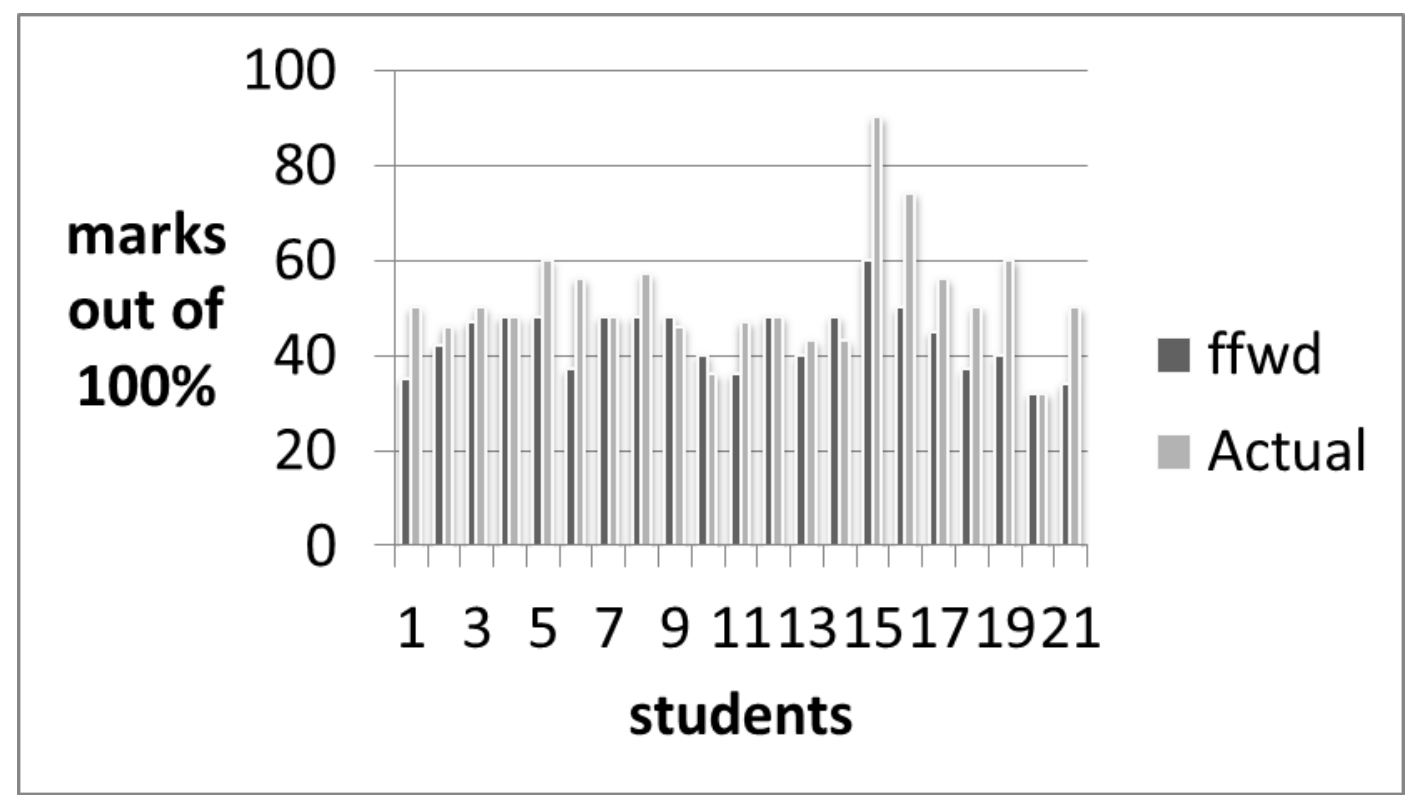

The most significant impact of the introduction of the project from our perspective has been confirmed by the students themselves. They stated the following in response to the question, 'What have you learned from the Feedforward project?'

I found that the feedback emphasised the good and not so good parts of the work so that adjustments to the work are made with confidence. 
How to set my references out and how to write in the correct manner, and it also put me at ease that I wasn't doing it wrong.

It was very useful to get an appreciation of how our work would be marked, especially as it was our first assignment.

By submitting a draft the feedback helped me to go into more depth with my assignment.

That I hadn't read around the subject enough and needed to work on referencing.

Students evaluated Feedforward positively and the attrition rate has reduced from $21 \%$ in 2007 (which was the highest in Wales) to 13\% in 2012 (the lowest in Wales). The university pre-registration nursing programme now has the highest retention rate in Wales. The nursing subject area has scored higher than any other nursing school in Wales over the last two years for student satisfaction in the National Student Survey and, although Feedforward is only one of a number of interventions aimed at promoting retention, it is undoubtedly significant in retaining student nurses on the pre-registration programme.

\section{Description of Numerate project}

All pre-registration nursing students have access to the interactive software programme 'safeMedicate' for all three years of their programme of study. 'safeMedicate' is an elearning package which enables students to develop, and HEls to assess, competence in drug calculations. While the students are aware that their drug calculation skills are assessed within their Personal Development Plan (PDP) portfolio, the knowledge that there will be a maths/numeracy assessment at their job interview was causing our students some concerns. In order to address that issue, additional numeracy support for drug calculations were offered to the relatively small cohort $(N=19)$ of second year nursing students who were returning to university after placement. It was necessary to assess the students' present ability regarding dosage calculations to be able to identify whether the students had improved with the intervention. For consistency of learning, all assessments were undertaken using 'safeMedicate'. 


\section{Methodology}

All Numerate sessions took place at the end of the university day during November and December and were in addition to the taught modular sessions of numeracy within the nursing curriculum. Attendance was voluntary and was open to all students in the cohort. The initial assessment via 'safeMedicate' took place at the start of the project, during session 1. Questions within 'safeMedicate' were not set by the project team but were downloaded to the student from a central bank of questions, thus eliminating any bias by way of the types of questions chosen. Details of the students' initial results were noted by the project team.

Following the initial assessment to identify the base-line numerical knowledge of the group, the subsequent Numerate sessions were tailored to address these skills gaps, as well as any numerical deficits self-identified by any student. Five face-to-face sessions were taught using an instructive approach combined with a collaborative, inclusive learning environment. Screencasts were produced, using a freeware computer programme 'Jing', which demonstrated a step-by-step approach to calculations (see Figure 5 for a screenshot of Screencast no. 9), together with accompanying worksheets (see Figure 6) for students to master specific techniques delivered within our project.

Figure 5. Screencast 9. Metric system and conversions between metric units.

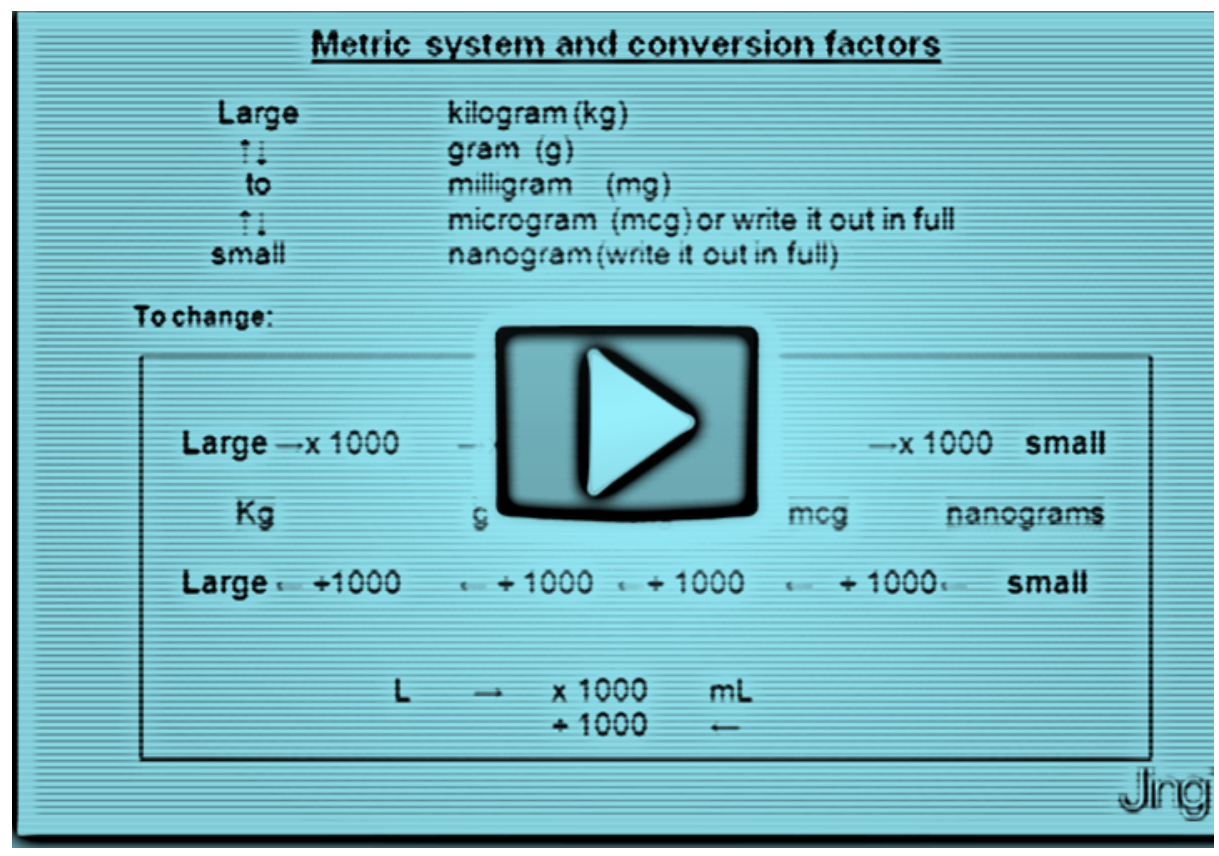




\section{Figure 6. Worksheet for Screencast 9. Metric system and conversions between}

\section{metric units.}

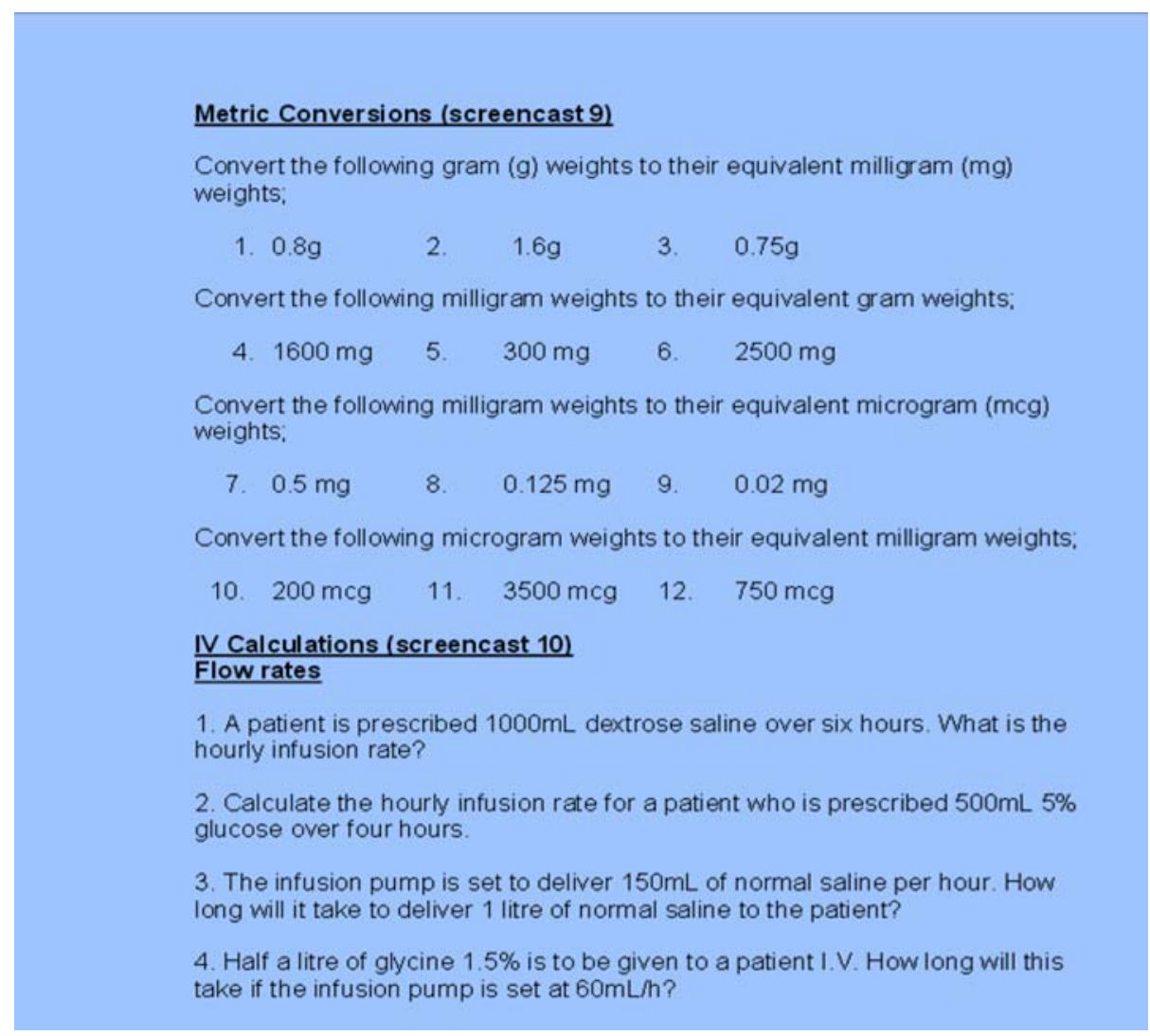

Additionally, access was freely available to the interactive software programme 'safeMedicate', which allowed students to practice their drug calculation skills as frequently as they needed. The sessions were all linked to the NMC Essential Skills Clusters (NMC, $2007 ; 2010)$ in relation to numeracy which ensured the sessions were relevant and linked to the requirements expected nationally of a $2^{\text {nd }} / 3^{\text {rd }}$ year nursing student. On average the attendance rate was $70 \%$ and above. In the final week, students were retested via 'safe Medicate' and the results of the pre and post assessments are detailed in figures 7 and 8 below. Maximum possible marks $=50$. 
Figure 7. Assessment results: Pre and Post Numerate sessions.

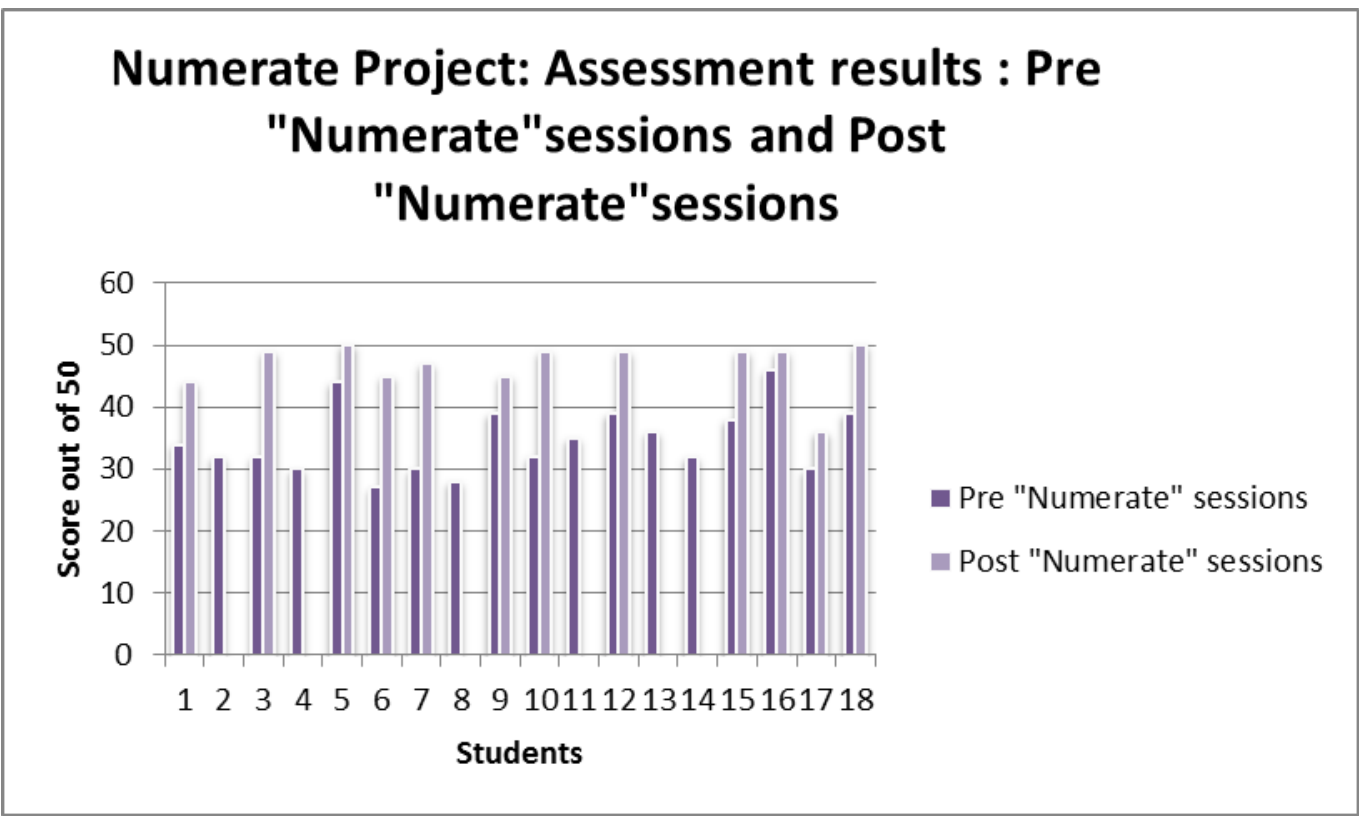

Figure 8. Assessment results: Pre and Post Numerate sessions.

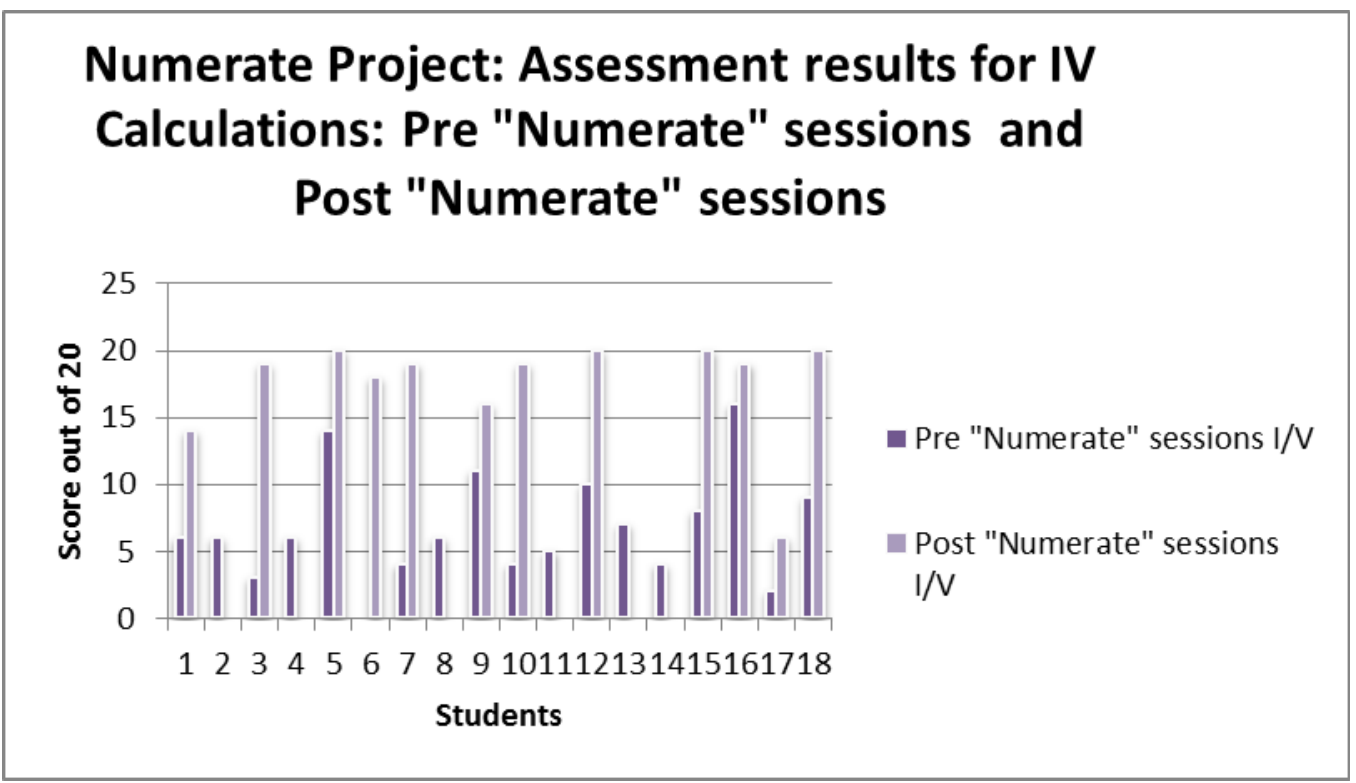

In addition to the taught sessions, focus groups were conducted on commencement and completion of the Numerate project to assess the impact. These sessions were conducted by a Professor of Nursing who had no input within the taught sessions, thus reducing bias within the questioning and enabling the students to contribute openly to the group sessions without fear of saying the 'wrong' things in front of their tutors. Five students attended each focus group. Questions posed during the first focus group related to students' confidence with their mathematical ability at the start of the project. For example: 
1. How do you feel about your maths ability right now as you've had your first assessment?

2. How does that make you feel now about going out onto the wards and having to do something like IV calculations?

3. In terms of confidence [with drug calculations] it's learning the formulas really that you need to know about?

4. Do you feel confident that you could trust the $[\mathrm{I} / \mathrm{V}]$ machine to do it for you?

Questions posed during the second focus group interview related to student confidence after the 'Numerate' sessions. For example:

1. Tell me about your experience with doing this new routine.

2. Do you think you're going to remember what you've learned when you go onto placement?

3. Do you think the actual numeracy sessions you've had with Alison and Celia have made a difference then?

\section{Evidence of impact of the Numerate project}

18 students undertook Pre Numerate session assessments and 12 (of the 18) completed Post 'Numerate' session assessments, which took place the week prior to the Christmas vacation. The six who did not complete the second assessment already had prior commitments. One student chose not to take either assessment. As can be seen from figure 7, all students who undertook Post 'Numerate' session assessments showed improvement on their Pre session results: the lowest improved by $6 \%$ and the highest improved by $36 \%$. Unfortunately, it has not been possible to compare the statistical significance of these improved marks as this is the first year of testing within 'safeMedicate' for second year students. Previously the testing of students had been confined to first year students.

When examining just the assessment results for IV transfusion calculations (see Figure 8), which were highlighted as a major concern for participants, all students in the first focus group showed improvement on Pre session results: the lowest improved by $15 \%$ and the highest improved by $90 \%$. 
All students who attended a minimum of four Numerate sessions were issued with a University Certificate of Attendance. The certificate can be added to the student's portfolio which is shared with prospective employers at interview, thus increasing the possibility of employment.

The comments from the students who attended the initial focus group indicated that many of them had not used the 'safeMedicate' programme since their first year of study and were therefore 'scared' of using the formulae for intravenous infusions. They wanted to keep their skills up-to-date but their lives were busy with placements, assignments and the concerns of family life. Comments from the students who attended the final focus group indicated that they felt more confident with their drug calculation skills and that the additional numeracy support from the project made a big difference. Additionally the students found the mix of tutor skills beneficial as we were able to highlight both the mathematical and nursing perspective of drug calculations, as comments from the focus groups indicate:

I think it's good to have Celia who has a maths degree or whatever, then you've got Alison who is a nurse so she understands it from our point of view.

Alison can bring the nursing side into it so I think it's good to have that mixture.

\section{Conclusion}

Working collaboratively, the ASTs and nursing tutors provide developmental support for both study skills and numeracy to students to enable them to use feedback to facilitate success and therefore promote learning. Student attrition has reduced during the time period both projects have been offered to students. Feedforward promotes retention by engaging students in study from the start of the programme. As a proactive measure it aims to create links for the students between active engagement with the assessment process and the benefits of the student support services (particularly Academic Skills Tutors) in order to succeed in learning. When students understand the importance of working with Nursing Tutors and ASTs to develop their ability, it has an impact on their engagement with the educational process. Both projects were evaluated positively by students and they often ask for this type of exercise when they move from one level to 
another. Enabling students to see what is being asked of them in the assignment brief and what each level 'looks like' appears to be achieved better if academics and study skills tutors work together. The Numerate project improved the confidence and competence with drug calculations of those students who took part in the focus groups, particularly around intravenous infusions, and reduced their anxiety when working in clinical practice.

\section{References}

Boone, S. (2010) 'Thin skin, deep damage: addressing the wounded writer in the basic writing course', Arts and Humanities in Higher Education, 9,(2) pp. 227-242. Available at : http://ahh.sagepub.com/content/9/2/227 (Accessed: 2 March 2013).

Burke, D. (2011) “Now I've got the feedback, what do I do with it?', Strategies for students to get more out of tutor feedback', Practice and Evidence of Scholarship of Teaching and Learning in Higher Education, 6(1), pp. 43-60.

Coffin, C., Curry, M., Goodman, S., Hewings, A., Lillis, T. and Swann, J. (2003) Teaching academic writing. Abingdon: Routledge.

Cottrell, S. (2001) Teaching study skills and supported Learning. Basingstoke: Palgrave Macmillan.

Crabtree, H., Roberts, C. and Tyler, C. (2007) Understanding the problems of transition into higher education. Available at:

http://www.ece.salford.ac.uk/proceedings/papers/35 07.pdf. (Accessed: 7 February 2013).

Ganobcsik-Williams, L. (ed.) (2006) Teaching academic writing in U.K higher education: theories, practices and models. Basingstoke: Palgrave Macmillan.

Glaister, K. (2007) 'The presence of mathematics and computer anxiety in nursing students and their efforts on medication dosage calculations', Nurse Education Today, 27(4), pp. 341-347. 
Glyndŵr University (2011) Periodic review of pre-registration student nursing. Wrexham: Glyndwr University.

Glyndŵr University (2011/12 - 2013/14) Learning and teaching strategy 2011/12-2013/14. Wrexham: Glyndŵr University. Available at:

http://glynfo.glyndwr.ac.uk/file.php/51/Strategies/GlyndwrLearningAndTeachingStrategyPublic.pdf (Accessed: 24 November 2013).

Groves, M., Bowd, B. and Smith, J. (2010) 'Facilitating experiential learning of study skills in sports students', Journal of Further and Higher Education, 34(1), pp. 11-22.

Hattie, J. and Timperley, H. (2007) 'The power of feedback', Review of Educational Research, 77(1), pp. 81-112. American Educational Research Association and Sage. Available at: http://rer.sagepub.com/content/77/1/81.full.pdf+html (Accessed: 16 July 2013).

Johnston, B. (2010) The first year at university: teaching students in transition. Maidenhead: Open University Press.

Knowles, M.S., Holton, E.F. and Swanson, R.A. (1998) The adult learner. $5^{\text {th }}$ edn. Woburn, Mass: Butterworth-Heinemann.

Moon, J. (2005) 'Putting writing at the centre', ESCalate Bulletin, Issue 2. Available at: http://escalate.ac.uk/2067 (Accessed: 10 January 2012).

National Audit Office (2007) Staying the course: the retention of students in higher education. London: The Stationery Office.

National Union of Students (2012) NUS Charter on academic support. Available at: http://www.nusconnect.org.uk/campaigns/highereducation/learning-and-teachinghub/academicsupport/ (Accessed: 30 January 2012).

Nursing and Midwifery Council (2007) Guidance for the introduction of the Essential Skills Clusters for pre-registration nursing and midwifery programmes. London: NMC. 
Nursing and Midwifery Council (2010) Standards for pre-registration nursing and education, Essential Skills Clusters and guidance for their use (guidance G7.1.5b), pp. 1-41, London: NMC

Roykenes, K. and Larsen, T. (2010) 'The relationship between nursing students' mathematics ability and their performance in a drug calculation test', Nurse Education Today, 30(7), pp. 697-701.

Thomas, L. (2012) Building student engagement and belonging in higher education at a time of change: final report from the What Works? Student Retention and Success Programme York: Higher Education Academy.

Tinto, V. (1975) 'Dropout from higher education: a theoretical synthesis of recent research', Review of Educational Research, 45(1), pp. 89-125.

Walsh, K.A. (2008) 'The relationship among mathematics anxiety, belief about mathematics, mathematics self-efficacy and mathematics performance in associate degree nursing students', Nursing Education Perspectives, 29(4), p. 226-229.

Weaver, M.R. (2006) 'Do students value feedback? Student perceptions of tutors' written response', Assessment and Evaluation in Higher Education, 31(3), pp. 379-394.

Wingate, U. and Andon, N. (2011) 'Embedding academic writing instruction into subject teaching: A case study', Active Learning in Higher Education, 12(1), pp. 69-81.

Yorke, M. (2003) 'Formative assessment in higher education', Higher Education, 45(4), pp. 477-501.

\section{Author details}

Celia Butters is an Academic Skills Tutor at Glyndŵr University and a Fellow of the Higher Education Academy. She and colleagues were instrumental in establishing the University's Academic Study Skills Centre and Celia is passionate about 
empowering students to develop their academic and mathematical ability. Her research areas of interest are maths and drug calculation skills.

Sheila Kerfoot is a lecturer in Early Childhood and Family Studies at Glyndŵr University. She and colleagues were instrumental in establishing the University's Academic Study Skills Centre. She is a Fellow of the Higher Education Academy, and her research interests lie in students' acquisition of academic writing skills.

Peggy Murphy is an adult nurse lecturer in the School of Health Sciences at Bangor University. Her research interests include the Higher Education Academy themes of retention and success and assessment and feedback. She is particularly interested in designing learning experiences that utilise assessment and feedback for learning. She is currently collaborating with colleagues from Bangor University and Whitirea College New Zealand in order to create online bilingual and bicultural learning support packages for Welsh and New Zealand student nurses. Peggy is a Fellow and an Academic Associate with the Higher Education Academy.

Alison Williams MA Ed, BSc(Hons), DN, RN (Adult), DipN, PGCPD, FHEA is a Senior Nurse Lecturer at Glyndŵr University. Alison has a background in community nursing and has worked as a district nurse in North Wales, she is also Programme Leader for Community Specialist Practice at Glyndŵr University. Alison teaches on both the pre and post registration nursing programmes and has a keen interest in research around the teaching of drug calculations to pre registration nursing students. 